\title{
KERATINS AND SKIN DISORDERS
}

\author{
K. SRIDHAR RAO ${ }^{1}$, K. K. RAJA BABU ${ }^{2}$ and P. D. GUPTA ${ }^{1 *}$ \\ Centre for Cellular and Molecular Biology, Hyderabad 500 007, India, and *Department of Dermatology, \\ Gandhi Medical College/Gandhi Hospital, Hyderabad 500 029, India
}

Accepted 5 January 1996

\begin{abstract}
The epidermal keratinocytes express two major pairs of keratin polypeptides. One pair (K5/K14) expressed specifically in basal generative compartment and the other (K1/K10) expressed specifically in the differentiating suprabasal compartment. The switch in the expression of the keratins from proliferating to differentiating compartment indicates the changes that occur in the keratin filament organization which in turn influences the functional properties of the epidermis. Proper regulation of keratin gene expression and the filament organization are absolutely necessary for normal functioning of the skin. Keratin gene mutations can influence the filament integrity thereby causing several heritable blistering disorders of the skin such as epidermolysis bullosa, bullous icthyosiform erythroderma, etc. Changes in the keratin gene expression may lead to incomplete differentiation of the epidermal keratinocyte, causing hyperproliferative diseases of the skin such as psoriasis, carcinomas, etc. This review briefly describes the changes in keratin structure or gene expression that are known to result in various disorders of the skin.

(C) 1996 Academic Press Limited
\end{abstract}

KEYWORDS: epidermis; keratinocytes; filament organization; mutation; expression; skin diseases

\section{INTRODUCTION}

The skin is one of the largest and perhaps the most complex organs of the human body and provides a protective interface between the organism and the environment. It is adapted to withstand a variety of physical, chemical and biological trauma, and acts as a thermoregulator and as a transducer of environmental information (Fuchs and Coulombe, 1992). Histologically, the skin is divisible into an outer epidermis, a middle dermis and an inner hypodermis. The epidermis is entirely cellular and is made of cells that are different both structurally and functionally (Bowden et al., 1987). Central to this variegated cell population are keratinocytes, the epithelial cells that produce keratin. Keratinocytes are generated by mitosis in the basal or germinative layer and migrate outwards through successive stages of differentiation (spinous, granular and horny layers) towards the surface where they are cornified and shed. The horny layer is composed of flattened and fully keratinized cells that are devoid of nuclei. Transition from the living

\footnotetext{
*To whom correspondence should be addressed.
}

1065-6995/96/040261+14\$18.00/0 granular layer to the anucleate horny layer is rather rapid (Fischer et al., 1991). In addition to keratinocytes, the epidermis contains three more cell types (Fig. 1), the neural crest emanated pigment cells or melanocytes, the bone marrow derived langerhans cells and the receptors of touch, the merkel cells (Priestly, 1993).

All eukaryotic cells contain a complex cytoskeleton composed of three different structural proteins: actin-containing microfilaments $(6 \mathrm{~nm}$ in diameter); tubulin-containing microtubules (25 nm diameter); and intermediate filaments (IF) (10 nm diameter) (Achtstatter et al., 1986; Steinert and Bale, 1993). Based on information about gene structure and protein sequence data, the IF proteins are classified into six subtypes: type I and II-keratins; type III-vimentin, peripherin, desmin and GFAP; type IV- $\alpha$-internexin and neurofilaments; type V-lamins; and type VInestin (Parry and Steinert, 1992; van de Klundert et al., 1993). Of all the IF proteins, keratin IFs are the most complex and are considered as the hallmark proteins of epithelial cell differentiation (Singh and Gupta, 1994b). 


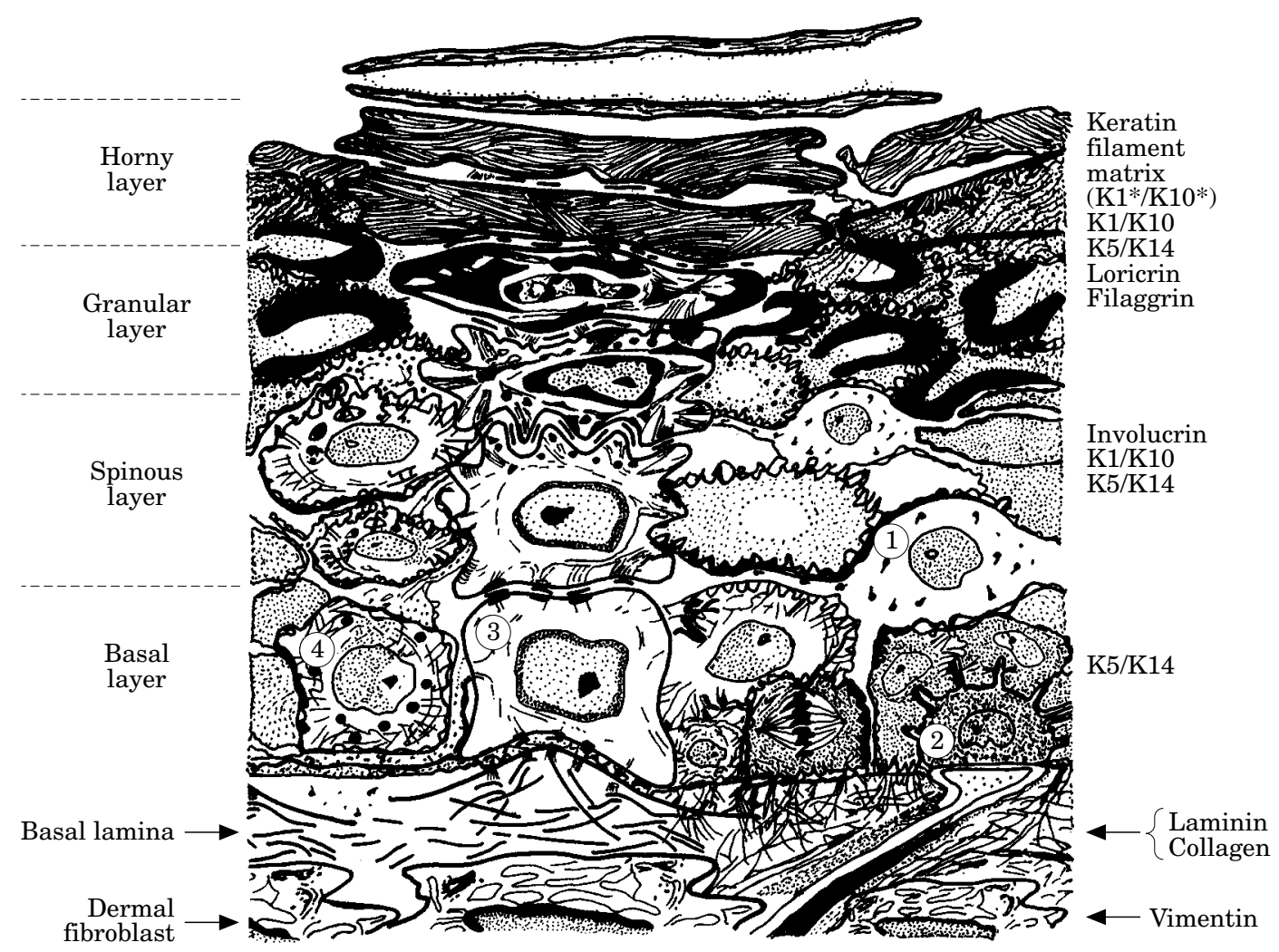

Fig. 1. Schematic diagram of epidermis showing different cell layers and cell types. Also depicted are changes in keratinocyte morphology and alterations in the gene expression of major structural proteins during the progression of differentiation. Basal keratinocytes express proliferation specific keratins K5 and K14 pair and as the differentiation proceeds it is gradually replaced by differentiation specific K1/K10 pair. Langerhans cell (1), Merkel cell (2), keratinocyte (3), and melanocyte (4) are also shown.

Keratinization of the epidermal cells is a tightly regulated multistep differentiation programme that results in cellular stratification. The basal keratinocytes divide and the resulting daughter cells migrate outwards and differentiate. Two major pairs of keratins get expressed in the epidermis-one expressed specifically in the dividing basal cells; and the other in the suprabasal cells that mark the beginning of cell differentiation and in the cells above (Fig. 1). During the epidermal cell migration, the induction of markers for a specific stage in epidermal differentiation is coupled with the repression of markers expressed at the preceding stage (Dlugosz and Yuspa, 1993). Epidermal differentiation also involves induction of proteins such as involucrin, epidermal and keratinocyte transglutaminase, filaggrin and loricrin, all of which are necessarily expressed in the upper layers of the epidermis (Fuchs and Green, 1980; Eckert and Rorke, 1989).

\section{Keratins}

The keratins are a complex family of proteins that form the IF system in epithelial cells (Moll et al.,
1982). The keratin family consists of about 30 polypeptides each coded by a distinct gene (Fuchs et al., 1987). The keratin IF genes have been found to be localized on different chromosomes. In general, type I keratin genes are located in two clusters on chromosome 17, one cluster on the short arm and another on the long arm. The type II keratins are localized in a single cluster on chromosome 12 (Bowden, 1993). Keratin expression is highly heterogenous and varies according to the epithelial cell type, period of embryonic development, stage of epithelial cell differentiation, disease state and cellular growth environment (Eichner et al., 1984). Keratins have been shown to be the first differentiation proteins that are expressed in embryos (Brulet et al., 1980; Singh and Gupta, 1994a). Indeed, keratins have been identified to form discrete filaments in the 2 to 8 cell embryo stage in golden Hamsters (Planche et al., 1989).

The protective function of the skin in general is a result of the cellular arrangement within the epidermis and the building up of extensive keratin cytoskeletal network (Fuchs, 1993). The intermolecular protein interactions that take place in the early stages of the assembly of epidermal 


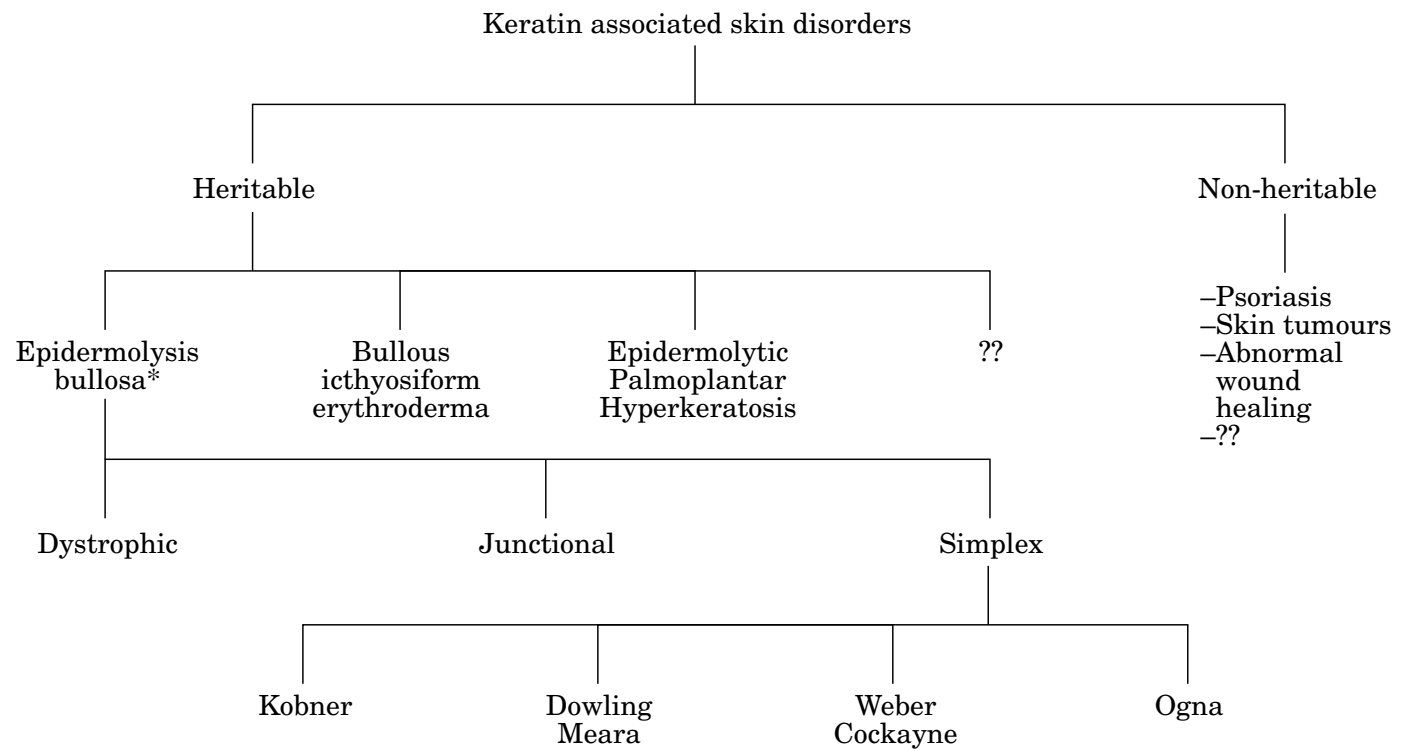

Fig. 2. Flow sheet depicting keratin associated skin disorders both heritable and non-heritable. *Around 23 variants are recognized based on their clinical and histological appearance.

keratins are remarkably stable and thus enhance the stability of keratins (Fuchs, 1990). Epidermal keratins also impart mechanical integrity and structure to the epidermis (Coulombe and Fuchs, 1991). The proper regulation of keratin gene expression and the formation of functional keratin IF network are essential for normal epidermal function (Bowden, 1993). Tampering with keratin synthesis leads to alterations in cell movement or cell differentiation and hence the subsequent function (Vassar et al., 1991; Singh and Gupta, 1994a). About 50 different skin disorders are known (Fig. 2) to result from changes in keratin filament appearance and organization (Griffiths, 1991). It has been shown that defective filament organization in the basal cells of transgenic mice results in inadequate stratification (Vassar et al., 1991). Mutations in keratin genes are found to be responsible for several skin disorders (see below).

\section{Molecular organization of keratin filaments}

The common denominator of all IF proteins is a central $\alpha$-helical rod domain containing about 310-315 amino acid residues. However, the flanking non-helical ends are variable from one IF protein to another. These variable regions contribute for the variation in the molecular mass of IF proteins (Fig. 3). The $\alpha$-helical rod domain is highly conserved both in size and secondary structure. Keratins being obligatory heteropolymers, at least one type I (acidic) and one type II (basic-neutral) chains are required for filament assembly (Hatzfield and Franke, 1985; Singh and Gupta, 1994b). The basic subunit of keratin filaments is a heterotypic tetramer of two polypeptide chains of each type I and type II keratins. The IF dimer comprises of a coiled coil made of two parallel polypeptide chains in an axial register (Steinert, 1991) (Fig. 4). Fuchs et al. (1987) have shown that the tetramers (protofilament) are formed by an antiparallel array of two dimers. Two such tetramers form a protofibril and generally four such protofibrils assemble to form a filament of 8-10 nm (Fig. 5).

\section{Keratins in epidermal development}

Human embryonic epidermal development identifiable by histology, ultrastructure and biochemistry can be divided into (a) embryonic period (7-9 weeks), (b) epidermal stratification (9-10 weeks), (c) follicular keratinization (14 weeks), and (d) interfollicular keratinization $(\sim 24$ weeks). Keratins are found as early as by the $2-8$ cell embryo stage. In the embryonic period, the epidermis is represented by only basal and peridermal cell layers. An intermediate layer without any keratinization is seen in addition, in the epidermal stratification phase. In the follicular keratinization phase the epidermis stratifies into three layers with the formation of hair follicles which begin to keratinize and trichocyte keratins start to express themselves. 


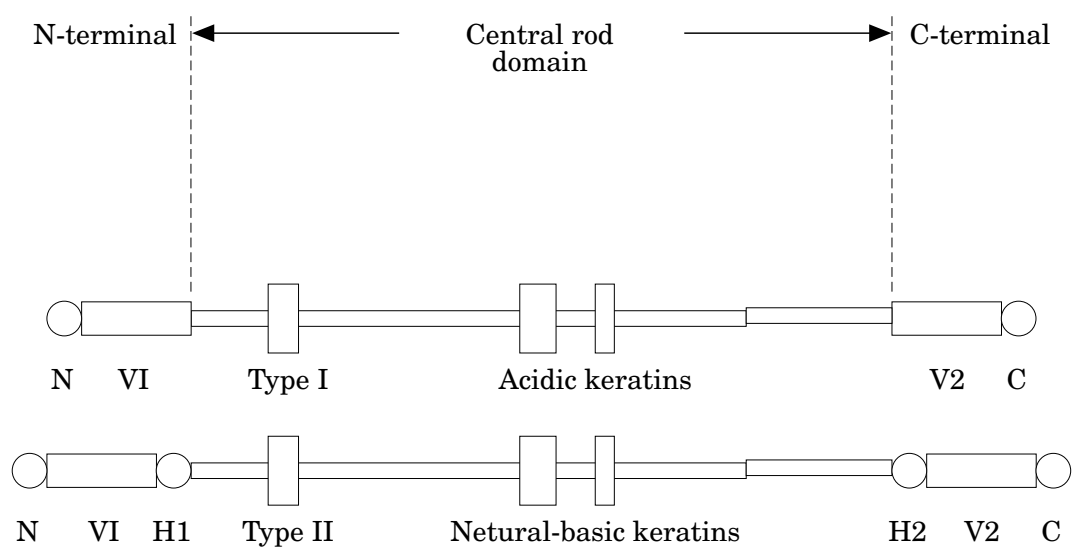

Fig. 3. A cartoon of keratin subunits depicting distinct domains in acidic (Type I) and basic-neutral (Type II) keratin polypeptides. Keratin subunits contain two distinct domains: (a) a central $\alpha$ helical rod domain that is conserved in all IF proteins and (b) non-helical $\mathrm{N}$ - and C-terminal domains which contribute for the variation in size and function. $\mathrm{H} 1$ and $\mathrm{H} 2$ represent smaller globular domains on the $\mathrm{N}$ - or $\mathrm{C}$-terminal ends respectively. VI and V2 are longer globular domains present in both types of keratin polypeptides. In addition smaller globular domains at $\mathrm{N}$ - or C-terminal regions are also present as shown. (Adapted from Roop, 1987.)

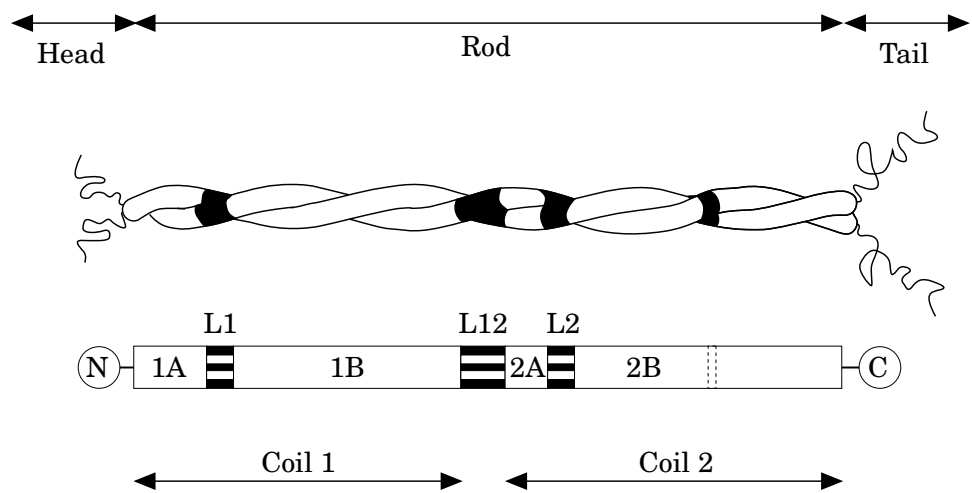

Fig. 4. Diagram of the basic structure of keratin IF dimer. The individual polypeptides have a central rod domain that is in turn seperated by non-helical linkers (L1, L12 and L2). The coiled coil dimer shown is a result of hydrophobic interaction between the 'in register' $\alpha$-helical domains of Type I and Type II keratin polypeptide chains. The linkers provide an 'oily seam' for the coiling of the central rod domain. (Adapted from Bowden, 1993.)

By interfollicular keratinization phase, basal, spinous, granular and cornified cell layers are all recognizable (Dale and Hollbrook, 1987).

\section{Keratins in skin, hair and nail}

Keratins constitute $30 \%$ of the protein in the basal cells of the stratified epithelium and $>85 \%$ in fully differentiated squames. Epidermis expresses predominantly two pairs of keratin polypeptides. Basal cells express K5 (type II basic keratin of $58 \mathrm{kDa}$ ) and K14 (type I acidic keratin polypeptide of $50 \mathrm{kDa}$ ). As the basal cells divide and enter the first suprabasal layer a downregulation of $\mathrm{K} 5$ and $\mathrm{K} 14$ expression and the induction of $\mathrm{K} 1$ and $\mathrm{K} 10$ expression occurs (Fuchs and Green, 1980; Moll et al., 1982). The type II keratin K1 (67 kDa) and type I keratin K10 (56.5 kDa) are only synthesized in differentiating epidermal cells. This synthesis continues up to 4-8 spinous cell thickness and represents one of the earliest changes indicating the commitment of the cell to terminal differentiation. This switch in synthesis to differentiation-specific keratins correlates well with increased bundling of keratin filaments at the basal suprabasal transition (Steinert and Roop, 1988). Filament assemblies in vitro have demonstrated that $\mathrm{K} 1$ and $\mathrm{K} 10$ selfaggregate more than the K5-K14 pair, and that the K1-K10 pair are less easily solubilizable (Fuchs, 1990). Biochemically, type I and type II keratin pairs that are co-expressed in basal cells have peptide repeats rich in serine whereas those expressed in differentiated cells have glycine-rich 


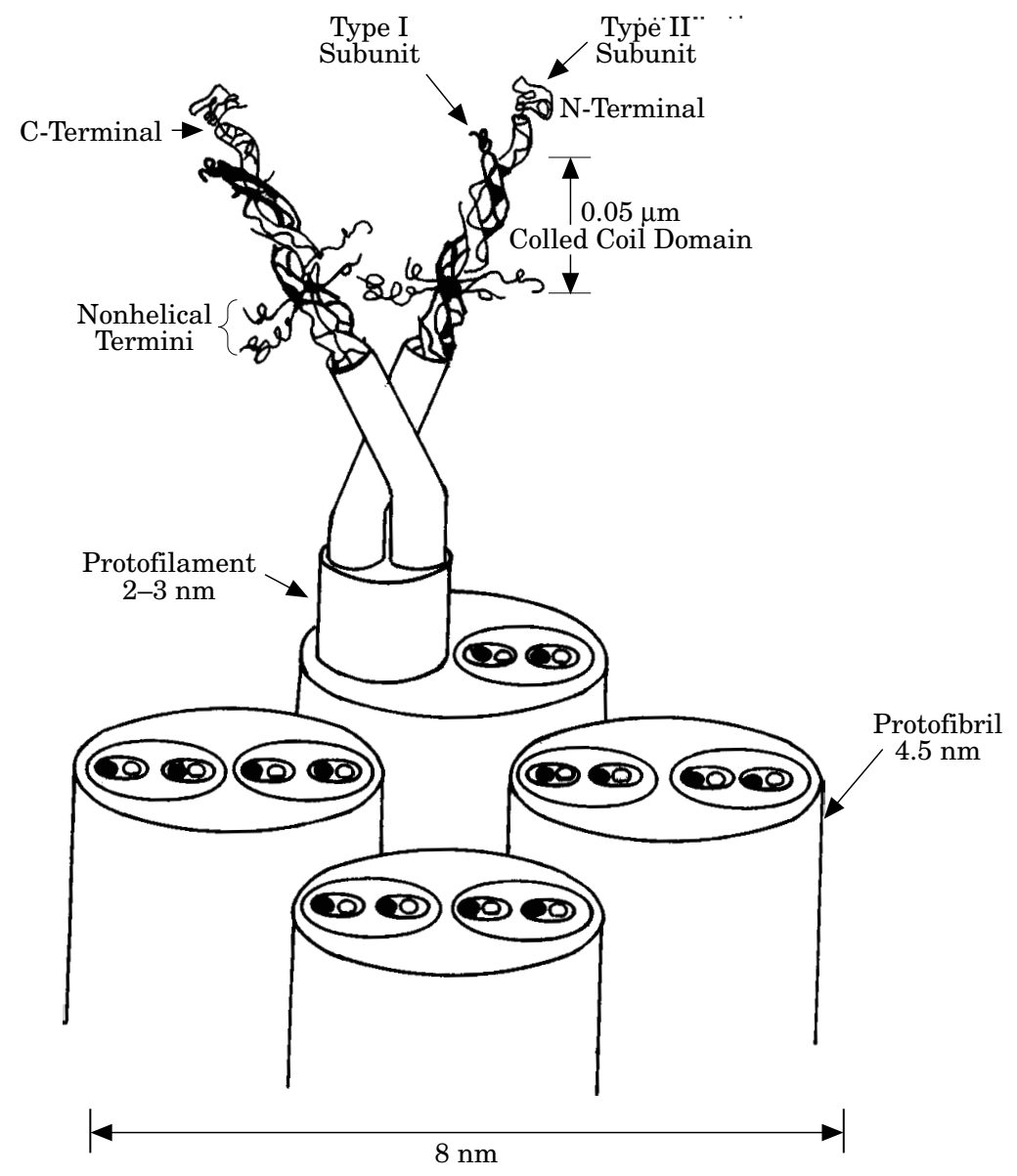

Fig. 5. Schematic representation depicting the organization of $8-10 \mathrm{~nm}$ keratin IF. Each protofilament (2-3 nm) is formed by antiparallel arrangement of two dimers. Two such protofilaments form a protofibril (4-5 nm). Generally four such protofibrils form a filament $(8-10 \mathrm{~nm})$.

sequences (Roop, 1987). This change in the basalsuprabasal-specific keratin polypeptide expressions may be essential for filament stability. In a natural situation several accessory proteins also play a pivotal role in the supramolecular organization of keratin filaments.

The hairs and nails, which are epidermal appendages, exhibit a complex morphology. The outer root sheath of hair follicle is a keratinizing epithelium and expresses a different set of keratin polypeptides $\mathrm{K} 6$ and $\mathrm{K} 16$ in addition to K5/K14. The upper outer root sheath contiguous with the epidermis expresses $\mathrm{K} 1$ and $\mathrm{K} 10$ suprabasally but the expression of these keratins is reduced in the region just above the sebaceous gland (Abling et al., 1992; Bowden, 1994). There is yet again some evidence that K17 and K19 are also expressed in hair follicles. Nails also show a similar profile of keratin expressions. In addition, hair and nail contain distinct subset of eight major hair-specific keratins, four acidic and four basic (low-sulphur $\alpha$ keratins) $\mathrm{HaKa} 1-4$ and $\mathrm{HaKb} 1-4$ and two minor keratins (HaX and HbX) (Heid et al., 1988a,b).

A fine balance must exist between the dividing and differentiating cells in the epidermis. Any modifications that result in altered expression or structural composition of keratin filaments may lead to pathological changes.

\section{Keratin and skin disease}

In this review, we would like to summarize some skin disorders that are the result of altered keratin expression or assembly. A great deal of information pertaining to the structural and functional properties of keratin filaments, filament assembly and network formations in health and disease is now available (Fuchs and Weber, 1994). Alteration in the expression of keratins experimentally or otherwise can result in drastic changes in a variety of cell functions (Gupta et al., 1992a,b; Singh and 
Gupta, 1994a; Singh et al., 1994). Interestingly, most of the genetically determined keratin disorders in skin are associated with mutations in the central rod domain (Fig. 6), which is crucial for filament formation. Perturbations in the filament formation or filament assembly may provide some cues to the cellular machinery that regulates the keratin expression per se and its influence on the whole gamut of division/differentiation programme in the epithelial cells in general and of the epidermis in particular (Fuchs, 1993). In fact, in the mitotic phase, in some of the epithelial cells, the keratin filaments reorganize into condensed noncytoskeletal spheroidally shaped structures distributed all through the cytoplasm (Horowitz et al., 1981; Knapp and Bunn, 1987). In addition to mutations, agents that can disrupt filament assembly through certain post-translational modifications such as phosphorylations, etc. (Celis et al., 1985; Gupta et al., 1990a) can influence keratin functions. Hormones such as estradiol and vitamin D3, growth factors such as EGF, drugs like retinoids, carcinogens or agents such as TPA may adversely influence filament assembly, thereby affecting the division and/or differentiation of epithelial cells (Gupta et al., 1990a).

The application of molecular biological techniques in recent times to the characterization of genes that encode for keratins and other structural proteins in epidermis has made it possible to understand the aetiopathogenesis of many skin diseases. The knowledge on the structure of keratin IF and their dynamics in living cells has made it possible to understand the variations in the constituent keratin proteins which are responsible for pathology.

The clinical severity of some examples of epidermolysis bullosa warrants development of non-invasive prenatal diagnostic techniques for identifying the potential risk of the disease (Christiano and Uitto, 1994). With the advances in molecular biological techniques it is now possible to develop certain DNA-based techniques for prenatal diagnosis of certain inheritable disorders of the skin. A change in the single nucleotide in (keratin) genes can now be detected using specific probes that are available. Specific defects in keratin expression, filament formation and assembly are thought to play a pivotal role in the causation of genetic disorders like Epidermolysis Bullosa Simplex (EBS), Bullous icthyosiform erythroderma (BIE) and palmoplantar keratoderma [Vorner] (McLean and Lane, 1995). Altered keratin expression appears to be secondary in hyperproliferative epidermal disorders like psoriasis but such altered expressions still serve as important markers of epidermal differentiation status (Bowden, 1993). Further, keratin expression also changes in skin carcinogenesis, although such disorders are unlikely to be the result of primary defects in the keratin genes themselves. Keratin expression has also been found to be abnormal in keloids and hypertropic scars (Ramakrishnan et al., 1995). It has also been proved that physical factors like light can influence the expression of keratins in a given situation (Horio et al., 1993; Smith and Rees, 1994).

\section{Epidermolysis bullosa}

Epidermolysis bullosa (EB) comprises a group of genetically distinct diseases characterized by blistering of skin and mucosae. The blisters may either result from minor mechanical trauma or apparently arise spontaneously. As many as 23 EB variants are recognized and delineated based on their clinical appearance, extracutaneous involvement, mode of inheritance and the level of the blisters (Coulombe and Fuchs, 1993).

Epidermolysis bullosa simplex (EBS) is generally transmitted autosomal dominantly although two rare variants with autosomal recessive inheritance exist. The dominant forms are most common. On the basis of differing clinical presentation, ultrastructural characteristics and keratin abnormalities, four major subtypes of EBS are identified. These are the Kobner, Dowling-Meara, WeberCockayne and Ogna variants. The four major EBS subtypes have a combined incidence of 1:25,000 (Fine et al., 1991).

It has been recognized that in EBS the cleavage occurs within the basal layer of the epidermis in a defined cytoplasmic zone located between the nucleus and the hemi-desmosomes. Characteristic ultrastructural features are seen in different forms of EBS. The presence of tonofilament clumps in the basal layer constitute an ultrastructural hallmark for EBS (Dowling-Meara) (Anton-Lamprecht and Snyder, 1982). These clumps are immunoreactive to antisera monospecific for basal layer-specific keratins (K5 and K14) (Vassar et al., 1991; IshidaYamamoto et al., 1994). Formation of tonofilament clumps precede blistering. Tonofilament clumping is not seen in Kobner, Weber-Cockayne or Ogna variants of EBS, although changes in the keratin filament network of epidermal basal cells have been described in some of them (Coulombe and Fuchs, 1993).

It is now clear that EBS may have a defect in keratins as its genetic basis (Coulombe et al., 1991). 


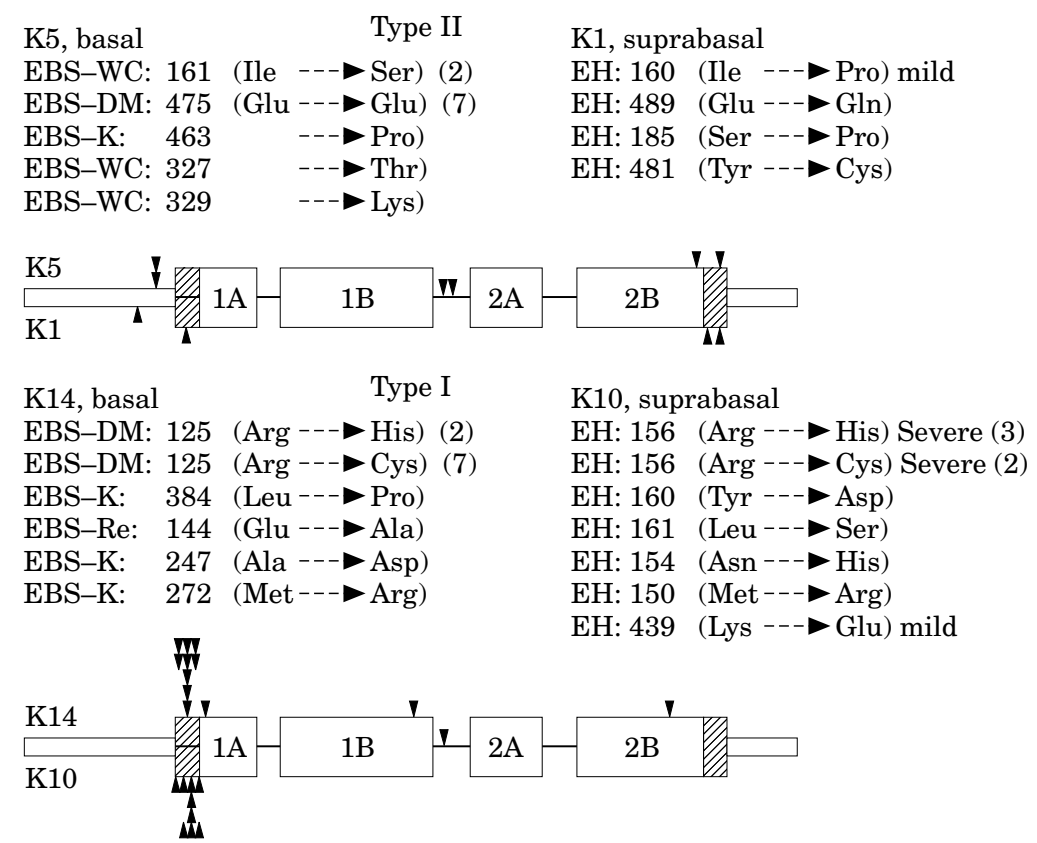

Fig. 6. Diagram showing the correlation between the location of various mutations and disease in several keratin-associated genetic disorders of skin. The details of the polypeptide domains shown are as in Fig. 4. Arrow heads depict the position of point mutations resulting in a single amino acid change shown in diseases such as EBS (K5 and K14) and EH (K1 and K10). Most of these mutations alter the integrity of the filament. (Adapted from Fuchs and Weber, 1994.)

Studies on the pathogenesis of EBS (DowlingMeara) represent the prototype for much that has been learnt about other type of EBS. Keratin mutation studies involving EBS cell culture and transgenic mice experiments strongly suggest that the manifestations of at least some examples of EBS are due to perturbations in the architecture of K5 and K14 keratin filament network in the basal cells of epidermis. Point mutations in either K5 or $\mathrm{K} 14$ coding sequence have recently been discovered in several instances of EBS (Coulombe et al., 1991; Lane et al., 1992). These mutations are responsible for the manifestation of EBS is supported by two lines of evidence (Fuchs and Weber, 1994). First, chromosomal linkage analysis experiments have mapped the genetic defect in three different EBS kindreds to either the long arm of chromosome 17 (Bonifas et al., 1991; Ryyaner et al., 1991; Hovnayian et al., 1993) at a location known to contain a cluster of type I keratin genes including $\mathrm{K} 14$, or the long arm of chromosome 12 at a location where a cluster of type II keratin gene including K5 are located. Secondly, genetic engineering of the specific EBS (Dowling-Meara) point mutations in the cloned K14 cDNA, followed by testing in vivo and in vitro have proved that these specific mutations can cause the tonofilament clumping and shortening of keratin filaments that are the diagnostic markers of the disease
(Coulombe et al., 1991; Letai et al., 1993). These data prove that aberrant heterodimer formation compromises filament integrity of the basal keratinocytes and results in disease expression (Singh and Gupta, 1994a). Transgenic experiments indicate that the severity of the clinical disease correlates with the degree of disruption of filament formation in vitro (Coulombe and Fuchs, 1993). Initial studies by Coulombe et al. (1991) have characterized the K14 mutations in two EBS (Dowling-Meara) patients. At amino acid 125 (the amino end of the rod domain of K14) they found arginine (Arg) to cystine (Cys) and arginine to histidine (His) mutations in half the K14 mRNAs. Subsequent studies (Rugg et al., 1993; Letai et al., 1993) have found that point mutations of Arg (331) to Cys or His in K5 and valine (270) to methionine in K14 are generally associated with EBS. Both these mutations localize in $\mathrm{L} 12$ linker region (Fig. 6) that bisects the $\alpha$-helical rod of the intermediate filaments indicating that the structural integrity of keratin intermediate filaments may be defective in the basal cells. The non-helical linker region also plays a significant role in filament integrity (Chan, 1994). Lane et al. (1992) have reported a complementary mutation in $\mathrm{K} 5$, a change from glutamic acid to glycine in the helix termination peptide. The two conserved helix boundary peptides are essential for keratin filament assembly. 
Bonifas et al. (1991) found genetic linkage of EBS (Kobner) to chromosome 17 and elucidated a point mutation $(\mathrm{T}-\mathrm{C})$ within exon 6 of keratin 14 gene. This mutation results in a leucine to proline change in keratin 14 polypeptide. Humphries et al. (1990) have demonstrated linkage in one of generalized EBS (Kobner) kindred to chromosome 1q although this linkage is less well elucidated. However, the derangements of keratin biology in localized EBS are not clear. In one with localized EBS (Weber-Cockayane), linkage to chromosome 12 near the K5 gene was found (Bonifas et al., 1991). Enhanced tonofilament condensation in the basal cell has been observed in localized EBS (Haneke and Anton-Lamprecht, 1982).

\section{Bullous icthyosiform erythroderma (BIE)}

BIE is a rare autosomal dominant disorder of cornification with a prevalence of approximately $1: 100,000$ to $1: 300,000$ (Bale et al., 1993). At least one half of the cases are sporadic and presumed to be the result of new mutations in keratin gene (Goldsmith, 1976). The disease manifests itself shortly after birth and is characterized by generalized erythema, scaling and blister formation, especially at sites of trauma and friction. With time blisters cease to appear and the skin becomes keratotic and even verrucous, particularly in the flexural areas, knees and elbows. Hyperkeratosis of palms and soles sometimes occurs.

With light microscopy BIE affected skin shows a tremendous thickening of stratum corneam and vacuolar degeneration of the upper epidermis (epidermolytic hyperkeratosis). Additionally, the epidermis may show the presence of coarse keratohyaline granules in the granular layer and epidermal acanthosis. Clumping of filaments is observed to begin with the first suprabasal layer under electron microscope. These aggregated filaments have been shown to be clumps of keratin intermediate filaments that contain the terminal differentiation specific keratins $\mathrm{K} 1$ and $\mathrm{K} 10$ (Ishida-Yamamoto et al., 1992).

Genetic linkage studies, gene sequencing and transgenic mice models indicate that $\mathrm{K} 1$ and/or K10 defects underlie the pathological basis of at least some examples of BIE. Linkage analysis has revealed linkage to markers on chromosome $12 \mathrm{q}$, the known locus for type II keratin gene clusters (Compton et al., 1992; Bonifas et al., 1992; Pulkkinen et al., 1993). Point mutations in either K1 or K10 genes of patients with BIE have been identified (Cheng et al., 1992; Chipev et al., 1992;
Rothnagel et al., 1992; Yang J-M et al., 1994; McLean et al., 1994). That these mutations disrupt keratin filament network in a dominant negative mode is also supported by in vitro experiments (Cheng et al., 1992; Chipev et al., 1992). Transgenic mice expressing a mutant K10 gene have been found to show phenotypic features suggestive of BIE (Fuchs et al., 1992). Interestingly as in EBS (Dowling-Meara) the severest disease producing point mutations affect amino acid residues localized at either the beginning or at the end of the rod domains (Coulombe and Fuchs, 1993). In three of the six cases studied, the arginine residue in position 156 of the K10 coding sequence was found to be affected.

There are still several gaps in our understanding of the molecular basis of BIE. Explanations are sought to understand the epidermal hyperkeratosis and acanthosis that are characteristic of the disease. It also remains to be elucidated why BIE pathology is localized on certain anatomical sites in the body. It is not known whether this involves altered expression of regional specific keratins like K2 or K9 or interplay of epigenetic factors like mechanical trauma. Other candidate genes for BIE disorders in skin include profilaggrin/filaggrin, involucrin and transglutaminase. It has been hypothesized that filaggrin abnormalities may contribute to keratin filament clumping and fragility because filaggrin has been found to promote keratin filament aggregation in vitro (Dale et al., 1987). A recent study (Ishida-Yamamoto et al., 1993) suggests that while filaggrin abnormalities are not primarily responsible for keratin filament clumping, they may have a contributory role in the altered epidermal structure and function in BIE. Linkage analysis pointed to the involvement of keratin type II gene (12 q 11-13) in icthyosis bullosa of Siemens a variant of BIE. Sequence analysis revealed the presence of mutations in $\mathrm{K} 2$ gene in patients with disease. Three different mutations were detected, one is the 1A domain and two is the 2B domain of the rod (Kremer et al., 1994).

\section{Epidermolytic palmoplantar keratoderma (Vorner) (EPK)}

This is the commonest type of heriditary palmoplantar keratodermas. Diffuse thickening of palms and soles becomes apparent at the age of 3 to 4 weeks. There is little or no spread of keratoderma on to the dorsal surface. Histologically all the characteristics of BIE are observed in the affected 
skin. Keratinocytes with an ultrastructurally abnormal tonofilament cytoskeleton are found in the histological specimens (Wevers et al., 1991). A genetic linkage analysis maps the defect to chromosome $17 \mathrm{q}$ as in EBS. Although the precise keratin defect in EPK is not known, K9 which is specifically expressed in the epidermis of palms and soles is thought to be defective (Reis et al., 1994).

\section{Other genodermatoses}

Dale et al. (1992) reported that the expression of differentiation specific keratins (K1 and K10) are greatly reduced and the proliferative specific (K5 and K14) and hyperproliferation specific (K6 and K16) keratins are generally enhanced in CHILD (Congenital Hemidysplasia with Icthyosiform erythroderma and Limb Defects) syndrome. In certain heritable disorders such as restrictive dermatopathy the skin expresses less of high molecular weight keratins and increased low molecular weight keratins such as 48 and $50 \mathrm{kDa}$.

\section{Skin disorders associated with keratinocyte hyperproliferation}

Skin abnormalities have also been described where keratinocyte hyperproliferation is either innate or incidental. Thus altered keratin expressions have been found in diseases as varied and different as psoriasis, lichen planus, lupus erythematosus, toxic epidermal necrolysis and Darier's disease.

Psoriasis is a chronic inflammatory and proliferative disorder of skin and in its typical presentation is characterized by asymptomatic sharply demarcated plaques of bright red erythema covered with a profusion of silvery white scales. The precise aetiology of the disease is not known but it is generally understood that non-genetic factors influence disease expression in genetically predisposed individuals.

Many studies (Thaler et al., 1980, Thewes et al., 1991; Bernard et al., 1992) have shown that in a majority of patients with psoriasis, the suprabasal keratins $\mathrm{K} 1$ and $\mathrm{K} 10$ are down-regulated and hyperproliferative keratins $\mathrm{K} 6$ and 16 (which are normally found in high turnover mucosal epithelia) are induced. The significance in the expression of K16 has been seen in the early development of psoriatic lesions where K16 protein detection precedes mitosis suggesting that it may render the cytoskeleton more plastic to enable cell movement. The qualitative changes in keratin expression suggests that there is not only abnormal keratinocyte differentiation but also abnormal keratinocyte proliferation in psoriasis. The authors' preliminary studies indicate that the low molecular weight keratins are pronounced in classical Lichen planus lesions compared to normal skin (unpublished observations).

\section{Wound healing}

Re-epithelialization is a pivotal event in wound healing. Basically, it involves migration and cornification of perilesional basal keratinocytes (Sten and Hepalman, 1988) across the wound bed to cover it. In the initial process of wound healing the basal keratinocytes express K6 and K16 keratin polypeptides (Tians et al., 1993), unlike the normal skin which expresses K5 and K14 pair.

In instances where there is extreme damage to the skin for e.g. as in thermal or chemical injury or in people who are genetically predisposed, abnormal wound healing takes place resulting in the development of hypertrophic scars or keloids (Kischev et al., 1992). Recent studies in our laboratory indicate that in keloid skin and in post-burn scars, there is an abnormal increase in the 58 and $50 \mathrm{kDa}$ keratin protein expression (Corresponding to K5 and K14 keratins) compared to hypertrophic scars and normal epidermis (Ramakrishnan et al., 1995). It appears that there is an increase in the message for K14 resulting in the presence of undifferentiated keratinocytes in keloids and post-burn scars (Ramakrishnan et al., 1995). This observation, although it includes keratinocyte matrix interations in wound healing, still suggests that altered keratin expression might influence abnormal wound healing to a significant degree.

\section{Skin tumours}

Abnormal keratin expression are also found in epithelial tumours, benign as well as malignant. Indeed, keratins may serve as biological markers for epithelial new growth (Gupta et al., 1992a,b). Transformed cells could trigger keratin filament rearrangements to be able to overcome cytoplasmic constraints imposed by cytoskeletal organization, thereby shutting off the differentiation process (Knapp and Bunn, 1987). In general, many skin tumours express keratin profiles of simple epithelia i.e. K8, 18 and K9. Additionally there is suppression of differentiation specific keratins. Tazawa et al. (1992) reported that carcinomas of sweat gland origin express various combinations of simple and stratified epithelial keratins. Perkins 
et al. (1992) found loss of K10 expression in some examples of basal and squamous cell carcinomas while in others, expression of $\mathrm{K} 8$ and $\mathrm{K} 18$ have been reported. In experimentally induced skin carcinomas in mice, Larcher et al. (1992) demonstrated K8 expression with a concomitant reduction in K13 expression. They suggest that increased synthesis of $\mathrm{K} 8$ can serve as a marker of terminal disease progression in the mouse skin.

The transformation of benign epidermal tumours to a malignant state generally involves the loss of $\mathrm{K} 1$ and $\mathrm{K} 10$ keratins (Kartasova et al., 1992). Some basal cell carcinomas have been found to express K17 and K19 (Markey et al., 1992). It also has been found that the transition of some squamous cell carcinomas of human and rodent origin to a more invasive metastatic spindle cell types also involves reorganization of cytoskeleton with functional loss of genes that control epidermal differentiation (Stoler et al., 1993). Sebacious carcinoma is another skin tumour where the low molecular weight keratin $(54 \mathrm{kDa})$ is preferentially expressed (Murata, 1993). In some dermatofibromas there is an increased expression of K6 and K16 along with altered expression of K14 (Stoler et al., 1989).

Doorbar et al. (1991) have reported that human papilloma virus (HPV) associated epithelial lesions, ranging from benign warts to invasive carcinomas, can destroy the cytokeratin matrix in the differentiating cells of the epidermis. HPV infected transgenic animal models have shown a marked reduction in the expression of K1/K10 (Tinsley et al., 1992). Pei et al. (1992) have shown that HPV-16 infected keratinocytes show greater expression of K13, K18 and K9 keratins. Proby et al. (1993) analysed the profiles of keratin expression in viral-induced warts and verrucous keratoses and malignant growths. They report loss of $\mathrm{K} 1$ and $\mathrm{K} 10$ and increase in simple epithelial keratins K8, $\mathrm{K} 18$ and $\mathrm{K} 9$ during advanced stages of malignancy. In contrast, K17 expression is found in much earlier stages in suprabasal hyperproliferative lesions of benign warts. Human epidermal keratinocytes in culture transformed with SV 40 downregulate the expression of $\mathrm{K} 5, \mathrm{~K} 6, \mathrm{~K} 14 / \mathrm{K} 15$ and $\mathrm{K} 16$ and $\mathrm{K} 17$ and express instead K8, K18 and K9 keratins as compared to normal keratinocytes (Hronis et al. 1984).

\section{Other factors influencing keratin expression}

(a) Chemical agents. Like hormones, retinoic acid can also influence the expression of genes through certain retinoic acid receptor elements (Evans, 1988; Jiang et al., 1990) and modulate proliferation and differentiation of epidermal keratinocytes in vivo and in vitro (Koppan et al., 1988). Retinoids are synthetic Vit A analogues and are used in a wide variety of dermatological disorders including tumours. Retinoids are found to alter the keratin gene expression and modulate filament formation by regulating the transcriptional or posttranslational modifications of keratin polypeptides. There have been conflicting observations on retinoid-induced altered keratin gene expressions. Rosenthal et al. (1993) have observed that acute or prolonged topical retinoic acid treatment of human skin in vivo affect the expression of $\mathrm{K} 6$ and $\mathrm{K} 13$ keratins but not K1 and K10. Fuchs (1990) has reported that the expression of differentiation specific K1 and K10 is blocked by Vit A. Retinoids may also influence expression of K6 and K16 (Kopan and Fuchs 1989). Many of the observed effects of retinoids are secondary (Stellmach and Fuchs, 1989) although there may be some alteration in levels of mRNA expression (Fuchs, 1990; Stellmach et al., 1991).

Other chemical agents and carcinogens like TPA and 1-Oleyl-2-acetyl glycerol block calcium mediated induction of $\mathrm{K} 1$ and $\mathrm{K} 10$ in mouse epidermal keratinocytes both at the protein and at the message levels, an effect that is blocked by bryostatin, a known inhibitor of protein kinase C (PKC). TPA mediated inhibition of $\mathrm{K} 1 \mathrm{mRNA}$ is also blocked by cycloheximide or actinomycin $\mathrm{D}$ indicating that PKC-induced protein may be involved in the regulation of keratin gene expression (Dlugosz and Yuspa, 1993) and epidermal differentiation. In the TPA induced epidermal tumours similar suppression of differentiation-specific keratins may occur. TPA may also modulate post-translational modifications of keratin polypeptide and thereby influence filament assembly and integrity (Gupta et al., 1992a)

Several growth factors that are produced by stromal cells influence keratinocyte proliferation and differentiation. Epidermal growth factor (EGF) and transforming growth factor alpha (TGF- $\alpha$ ) induce the activation of hyperproliferation associated K6 and K16 through specific nuclear proteins (Fuchs, 1990, Jiang, 1993). Calcium ions also play an important role in epidermal differentiation (Jaken and Yuspa, 1988). Calcium ions may alter the expression of differentiation specific keratins or alter the filament assembly and integrity. Studies in the authors' laboratory indicate that hormones like estradiol influence the differentiation of target tissues through the 
mediation of calcium ions (Gupta et al., 1990b). Vijayalakshmi and Gupta (1994) have shown that increased calcium levels in rodent vaginal epithelial cells regulate transglutaminase which in turn helps in cross-linking the keratin polypeptides during terminal differentiation.

(b) Physical agents. Certain physical agents such as irradiation also cause rapid alteration in the expression of skin keratins. Horio et al. (1993) have reported that in guinea pig skin, ultraviolet (UV) radiation increases the expression of basal layer specific keratins in suprabasal cells. The variation in keratin expression can be seen even at the message level. Smith and Reiss (1994) have observed wavelength dependent alterations in the expression of keratin mRNAs. They reported that keratinocytes upon irradiation with UVA (320$400 \mathrm{~nm}$ ) show lesser induction of K1/K10 transcription whereas $\mathrm{K} 5$ and $\mathrm{K} 14$ messages remain unaltered. In case of exposure to UVC $(<290 \mathrm{~nm})$ they found an increase in K5/K14 message, but not in $\mathrm{K} 1 / \mathrm{K} 10$, and on exposure to UVB (290-320 nm) all the keratin messages were increased. Thus, local alteration in keratin synthesis may influence disease expression in exposed skin.

\section{CONCLUSIONS}

The protective function of the epidermis is mainly dependent on the expression of specific keratin polypeptides and the keratin filament integrity. The variations in the expression of keratins from basal to cornified layers represent a functional organization rather than a mere histological stratification. Changes in the integrity of the keratin filaments or the expression of the keratin polypeptides that are result of gene mutations or alterations induced by a variety of chemical or physical agents adversely affect the functional properties of the keratinocyte, thereby resulting in various dermatological disorders. The precise knowledge about the factors that regulate tissue specific expression of keratin polypeptides may provide further insights into the understanding of these keratin associated skin diseases in general, and also pave the way for devising improved therapeutic strategies, either newer drug therapies or gene therapy. Developing keratin based diagnostic tools would help in prenatal diagnosis of certain heritable disorders of the skin, such as the ones discussed in this review.

\section{REFERENCES}

Abling FAG, EAdy RAJ, Leigh IM, 1992. Anatomy and organisation of human skin. In: Champion RH, Burton JL, Abling FAG, eds. Text Book of Dermatology, 5th edn. Oxford, Blackwell Scientific Publications, 49-123.

Achtstatter TM, Hatzfeld RA, Quinlan DC, Franke WW, 1986. Separation of cytokeratin polypeptides by gel electrophoretic and chromatographic techniques and their identification by immunoblotting. Methods Enzymol 134: 355-371.

Anton-LAmprecht I, SNyder UW, 1982. Epidermolysis bullosa herpetiformis Dowling Meara: Report of a case and pathogenesis. Dermatologica 164: 221-226.

Bale SJ, Compton JG, Digiovanna JJ, 1993. Epidermolytic hyperkeratosis. Seminars in Dermatology 12: 204-209.

Bernerd F, Magnaldo T, Darmon M, 1992. Delayed onset of epidermal differentiation in psoriasis. $J$ Invest Dermatol 98: 902-910.

Bonifas JM, Bare JW, Chen MA, Lie MK, Slater CA, GoldSMith LA, EPSTEIN EH JR, 1992. Linkage of the eidermolytic hyperkeratosis phenotype and the region of the type II keratin gene culster on chromosome 12. J Invest Dermatol 99: 524-527.

Bonifas JM, Rothman AL, EPSTEIn EH, 1991. Epidermolysis bullosa simplex: Evidence in two families for keratin gene abnormalities. Science 254: 1202-1205.

Bowden PE, Stark HJ, Breitkreutz D, Fusenig NE, 1987. Expression and modification of keratins during terminal differentiation of mammalian epidermis. Current Topics in Developmental Biology 22: 35-68.

BowDEn PE, 1993. Keratins and other epidermal proteins. In: Priestley GC, ed., Molecular Aspects of Dermatology. John Wiley, Chichester, pp. 20-54.

Brulet P, Babinet C, Kemler, R, Jacob F, 1980. Monoclonal antibodies against trophoectoderm specific markers during mouse blastocyst formation. Proc Natl Acad Sci USA 77: 4113-4117.

Celis JE, Fey ST, Larsen PM, Celis A, 1985. Preferential phosphorylation of keratins and vimentin during mitosis in normal and transformed human amnion cells. Ann NY Acad Sci 455: 268-281.

Chan YM, Yu QC, LeBlanc-Straceski J-J, et al., 1994. Mutations in the non helical linker segment L1-2 keratin 5 in patients with Weber-Cockayne epidermolysis bullosa simplex. J Cell Sci 107: 765-774.

Cheng J, Syder AJ, Yu QC, Letai A, Paller AS, Fuchs E, 1992. The genetic basis of epidermolytic hyperkeratosis: a disorder of differentiation specific epidermal keratin genes. Cell 70: $811-819$.

Chipev CC, Korge BP, Markova N, Bale SJ, Digiovanna JJ, Compton JG, Steinert PM, 1992. A leucine-proline mutation in the $\mathrm{H} 1$ subdomain of keratin 1 causes epidermolytic hyperkeratosis. Cell 70: 821-828.

Chipev CC, Yang JM, Digiovanna JJ, Steinert PM, Marekov L, Compton JG, Bale SJ, 1994. Preferential sites in keratin 10 that are mutated in epidermolytic hyperkeratosis. Am J Hum Genet 54: 179-190.

Christiano AM, UitTo J, 1994. DNA-based prenatal diagnosis of heritable skin disaeses. Arch Dermatol 1: 286-290.

Compton JG, DiGiovanna JJ, Santucci SK, et al., 1992. Linkage of epidermolytic hyperkeratosis to the type II keratin gene cluster on chromosome 12 q. Nature Gen 1: 301-305. 
Coulombe PA, Hutton ME, Vassar R, Fuchs E, 1991. A function for keratins and a common thread among different types of epidermolysis bullosa simplex diseases. J Cell Biol 115: $1661-1674$.

Coulombe PA, Hutton me, Letai A, Hebert A, Paller AS, Fuchs E, 1991. Point mutations in human keratin-14 genes of epidermolysis bullosa simplex patients: Genetic and functional analyses. Cell 66: 1301-1311.

Coulombe PA, Fuchs E, 1993. Epidermolysis bullosa simplex. Seminars in Dermatology 12: 173-190.

DALE BA, HolbrooK KA, 1987. Developmental expression of human epidermal keratins and filaggrin. Curr Topics in Dev Biol 22: 127-152.

Dlugosz AA, Yuspa SH, 1993. Coordinate changes in gene expression which mark the spinous to granular cell transition in epidermis are regulated by protein kinase C. $J$ Cell Biol 120: 217-225.

Doorbar J, Ely S, Sterling J, Mclean C, Crawford L, 1991. Specific interaction between HPV-16 E1-E4 and cytokeratins results in collapse of the epithelial cell intermediate filament network. Nature 352: 824-827.

ECKERT RL, Rorke EA, 1989. Molecular biology of keratinocyte differentiation. Environ-Health-Perspect 80: 109-116.

EICHNER R, Bonitz P, Sun TT, 1984. Classification of epidermal keratins according to their immunoreactivity, isoelectric point and mode of expression. J Cell Biol 98: 1388-1396.

Evans RM, 1988. The steroid and thyroid hormone superfamily. Science 240: 889-895.

Fine JD, BAUER EA, Briggaman RA, et al., 1991. Revised laboratory and clinical criteria for subtypes of inherited epidermolysis bullosa. A consensus report by the subcommittee on diagnosis and classification of the national epidermolysis bullosa registry. J Am Acad Dermatol 24: 119-135.

Fuchs E, Weber K, 1994. Intermediate filaments: structure, dynamics, function and disease. Ann Rev Biochem 63: 345382.

Fuchs E, Tyner AL, Giudice GJ, Marchuk D, Raychaudhury A, Rosenberg M, 1987. The human keratin genes and their differential expression. Curr Topics in Dev Biol 22: 5-34.

Fuchs E, Coulombe PA, 1992. Of mice and men: genetic skin diseases of keratin. Cell 69: 899-902.

FuChs E, GreEN H, 1980. Changes in keratin gene expression during terminal differentiation of the keratinocyte. Cell 19: 1033-1042.

Fuchs E, 1990. Epidermal differentiation: the bare essentials. J Cell Biol 111: 2807-2814.

Fuchs E, 1993. Epidermal differentiation and keratin gene expression. J Cell Sci Suppl 17: 197-208.

Goldsmith LA, 1976. The icthyoses. Prog Med Genet 1: 185-210.

Griffiths WAD, LEIGH IM, MARKs R, 1991. Disorders of keratinization. In: Champion RH, Burton JL and Ebling FJG, eds. The Text Book of Dermatology 5th edn. Vol. 2. Oxford, Blackwell Scientific Publications, pp. 1325-1390.

Gupta A, Malati T, Gupta PD, 1992a. Altered expression of keratin in epitheloid tumors. Curr Sci 62: 288-293.

Gupta A, Malati T, Gupta PD, 1992b. Intracellular proteins as tumor markers. Ind J Clin Biochem 7: 81-89.

Gupta PD, Swarup G, Reddy AG, 1990a. Modulation of phosphorylation and dephosphorylation of keratin and other polypeptides by estradiol $17 \beta$ in rat vaginal epithelium. FEBS Lett 273: 135-138.
Gupta PD, Relia SB, Bapu Rao S, Reddy AG, $1990 b$. Keratinization of rat vaginal epithelium V: Modulation of intracellular calcium by estradiol. J Steroid Biochem Mol Biol 37: 521-527.

HANEKe E, ANTON-LAMPRECHT I, 1982. Ultrastructure of blister formation in epidermolysis bullosa hereditaria: V Epidermolysis bullosa simplex localisate type WeberCockayne. J Invest Dermatol 78: 219-223.

HatzFeld M, Franke WW, 1985. Pair formation of cytokeratins: formation in vitro of heterotypic complexes and intermediate sized filaments by homologus and heterologus recombinations of purified polypeptides. J Cell Biol 101: 1826-1841.

Heid HW, Moll I, Franke WW, 1988. Patterns of expression of the trichocytic and epithelial cytokeratins in mammalian tissues. I. Human and bovine hair follicles. Differentiation 37: $137-157$.

Heid HW, Moll I, Franke WW, 1988. Patterns of expression of the trichocytic and epithelial cytokeratins in mammalian tissues. II. Concomittant and mutually exclusive synthesis of trichocytic and epithelial cytokeratins in diverse human and bovine tissues (hair follicle, nail bed and matrix, lingual papilla, thymic reticulum). Differentiation 37: 215-230.

Horio T, Miyauchi H, Sindhvananda J, SoH H, Kurokawa I, AsADA Y, 1993. The effect of ultraviolet (UVB and UVA) radiation on the expression of epidermal keratins. $\mathrm{Br} J$ Dermatol 128: 10-15.

Horwitz B, Kupfer H, EshHar Z, Geiger B, 1981. Reorganization of arrays of prekeratin filaments during mitosis. Exp Cell Res 134: 281-290.

Hovnavian A, Pollack E, Hilal L, Rochat A, Prost C, BARRANDON Y, Gossens M, 1993. A missense mutation in the rod domain of keratin 14 associated with recessive epidermolysis bullosa simplex. Nature Genetics 3: 327-332.

Hronis TS, Steinberg ML, Defendi V, Sun TT, 1984. Simple epithelial nature of some siman virus 40 transformed human epidermal keratinocytes. Cancer Res 44: 5797-5804.

IRWIN MCLEAN WH, LANE EB, 1995. Intermediate filaments in disease. Curr Opinion in Cell Biol 7: 118-125.

Ishida-Yamamoto A, LeIGH IM, LANE EB, et al., 1992. Selective expression of the differentiation specific keratins $\mathrm{K} 1$ and $\mathrm{K} 10$ in the tonofilament clumps of bullous icthyosis (epidermolytic hyperkeratosis). J Invest Dermatol 99: 10-25.

Ishida-YAmamoto A, McGrath JA, CAPMAn SJ, et al., 1993. Epidermolysis bullosa simplex (Dowling Meara type) is a genetic disease characterized by an abnormal keratin filament network involving keratins $\mathrm{K} 5$ and $\mathrm{K} 14$. J Invest Dermatol 97: 959-968.

JAKEN S, YUSPA H, 1988. Early signals for keratinocyte differentiation: role of calcium mediated inositol lipid metabolism in normal and neoplastic epidermal cells. Carcinogenesis (Lond) 9: 1033-1038.

Jiang CK, Magnaldo T, Ohtsuki M, Freedberg IM, BERNERD F, BLUMENBERG M, 1993. Epidermal growth factor and transforming growth factor alpha specifically induce the activation and hyperproliferation associated keratins 6 and 16. Proc Natl Acad Sci USA 90: 6786-6790.

Jiang TM, Epstein TK, Freedberg IM, SAmuels HH, BLumenBERG M, 1990. Nuclear receptors for retinoic acid and thyroid hormone regulate transcription of keratin gene. Cell Regul 1: 965-973.

Kartasova T, Roop DR, Yuspa SH, 1992. Relationship between the expression of differentiation specific keratins 1 and 10 and cell proliferation in epidermal tumor. Mol Carcinog 6: 18-25. 
KNAPP LW, BunN CL, 1987. The experimental manipulation of keratin expression and organisation in epithelial cells and somatic cell hybrids. Curr Top Dev Biol 22: 69-96.

KopAn R, Fuchs E, 1989. The use of retinoic acid to probe the relation between hyper-proliferation associated keratins and cell proliferation in normal and malignant epidermal cells. J Cell Biol 109: 295-307.

Kopan R, Trasaka G, Fuchs E, 1987. Retinoids as important regulators of terminal differentiation: examining keratin expression in individual epidermal cells at various stages of keratinization. J Cell Biol 105: 427-440.

Kremer H, Zeewen P, McLean WHI, et al., 1994. Icthyosis bullosa of simens is caused by mutations in the keratin $2 \mathrm{e}$ gene. J Invest Dermatol 103: 286-289.

Lane EB, Ruggs EL, Nausaria H, et al., 1992. A mutation in the conserved helix termination peptide of keratin 5 in hereditary skin blistering. Nature 356: 244-246.

Larcher F, Bauluz C, Diaz-Guerza M, Quintanilla M, Conti CJ, Ballestin C, Jorcano JL, 1992. Aberrant expression of the simple epithelial type II keratin 8 by mouse skin carcinomas but not papillomas. Mol Carcinog 6: 112121.

Letai A, Coulombe PA, McCormick MB, Yu QC, Hutton E, Fuchs E, 1993. Disease severity correlates with position of keratin point mutation in patients with epidermolysis bullosa simplex. Proc Natl Acad Sci USA 90: 3197-3201.

Markey AC, Lane EB, Macdonald DM, Leigh IM, 1992. Keratin expression in basal cell carcinomas. $\mathrm{Br} J$ Dermatol 126: $154-160$.

McLean WH, Eady RA, Dopping-Hepenstal PJ, et al., 1994. Mutations in the rod $1 \mathrm{~A}$ domain of keratins 1 and 10 in bullous congenital ichthysiform erythroderma (BCIE). J Invest Dermatol 102: 24-30.

Moll R, Franke WW, Schiller DL, Geizer B, Krepler R, 1982. The catalogue of human cytokeratins: Patterns of expression in normal epithelia, tumors and cultured cells. Cell 31: 11-24.

Murata T, Nakashima, Y, Takeuchi M, Sueishi K, Inamata H, 1993. The diagnostic use of low molecular weight keratin expression in sebaceous carcinoma. Pathol Res Pract 189: 888-893.

Parry DA, Steinert PM, 1992. Intermediate filament structure. Curr Opin Cell Biol 4: 94-98.

Pei XF, Leigh IM, Watt FM, 1992. Changes in type I keratin expression associated with HPV 16 transformation of human epidermal keratinocytes. Epith Cell Biol 1: 84-89.

Perkins W, Campbell I, Leigh IM, Mackie RM, 1992. Keratin expression in normal skin and epidermal neoplasm demonstrated by a panel of monoclonal antibodies. $J$ Cutan Pathol 19: 476-482.

Planche CE, Carma-fonesca M, David Ferreira JF, 1989. Cytokeratin filaments are present in golden Hamster oocyte and early embryos. Differentiation 42: 1-9.

Priestley GL, 1993. An introduction to the skin and its diseases. In Priestley GL, ed. Molecular Aspects of Dermatology. Chichester, John Wiley, pp. 1-17.

Proby CM, Churchill L, Purkis PE, Glover MT, Sexton CJ, LeIGH IM, 1993. Keratin 17 expression as a marker for epithelial transformation in viral warts. Am J Pathol 143: 1667-1678.

Pulkkinen L, Christiano AM, Knowlton RG, Uitto J, 1993. Epidermolytic hyperkeratosis (bullous congenital icthyosiform erythroderma). Genetic linkage to chromosome $12 \mathrm{q}$ in the region of the type II keratin gene cluster. $J$ Clin Invest 91: 357-361.
Ramakrishnan M, Prathibha V, Rao KS, Babu M, Gupta PD, 1995. Expression of keratin in post burn scars and keloids. Ann Mediterranean Burns Club (in press).

Reis A, Hennies HC, Langbein L, et al., Keratin 9 gene mutations in epidermolytic palmoplantar keratoderma (EPPK). Nature Genet 6: 174-179.

Roop DR, 1987. Regulation of keratin gene expression during differentiation of epidermal and vaginal epithelial cells. Curr Topics in Dev Biol 2: 195-208.

Rosenthal DS, Steinert PM, Chung S, Huff CA, Johnson J, Yuspa SH, Roop DR, 1991. A human epidermal differentiation specific keratin gene is regulated by calcium but not negative modulators of differentiation in transgenic mouse keratinocytes. Cell Growth Differ 2: 107-113.

Rothnagel JA, Dominey AM, DemPSey LD, et al., 1992. Mutations in the rod domains of keratins 1 and 10 in epidermolytic hyperkeratosis. Science 257: 1128-1130.

Rugg EL, Morley SM, SMith FJD, et al., 1993. Missing links: Weber cockayne keratin mutations implicate the L12 linker domain in effective cytoskeleton function. Nature Genet 5: 294-300.

Ryynanen M, Knowlton RG, Uitto J, 1991. Mapping of epidermolysis bullosa simplex mutation to chromosome 12 . Am J Hum Genet 49: 978-984.

SingH S, GuPTA PD, 1994a. Tampering with cytokeratin expression results in cell dysfunction. Epith Cell Biol 3: 79-83.

SingH S, GuPTA PD, 1994b. Intermediate filamentsHeterogenous expression pattern and modulation: can their role in structure and function of the cell be ascertained? Biol Cell 82: 1-10.

Singh S, Koke JR, Gupta PD, Malhotra SK, 1994. Multiple roles of intermediate filaments. Cytobios 77: 41-57.

SMith MD, ReEs JL, 1994. Wave length-specific upregulation of keratin mRNA expression in response to ultraviolet radiation. J Invest Dermatol 102: 433-439.

STEINERT PM, Roop DR, 1988. Molecular and cellular biology of intermediate filaments. Ann Rev Biochem 57: 593-625.

STEINERT PM, 1991. Organization of coiled-coil molecules in native mouse keratin 1/keratin 10 intermediate filaments: evidence for alternating rows of antiparallel in register and antiparallel staggered molecules. J Struct Biol 107: 157-174.

Steinert PM, Bale SJ, 1993. Genetic skin diseases caused by mutations in keratin intermediate filaments. Trends in Genet 9: 280-284.

Stellmach V, Leask A, Fuchs E, 1991. Retinoid mediated transcriptional regulation of keratin genes in human epidermal and squamous cell carcinoma cells. Proc Natl Acad Sci USA 88: 4582-4586.

Stellmach VM, Fuchs E, 1989. Exploring the mechanisms underlying cell type specific and retinoid mediated expression of keratins. New Biol 1: 305-317.

Stoler A, Duvic M, Fuchs E, 1989. Unusual patterns of keratin expression in the overlying epidermis of patients with dermatofibromas: biochemical alterations in the epidermis as a consequence of dermal tumors. J Invest Dermatol 93: $728-738$.

Stoler AB, Stenback F, Balmain A, 1993. The conversion of mouse skin squamous cell carcinomas to spindile cell carcinomas is a recessive event. J Cell Biol 122: 1103-1107.

Tazawa T, Ito M, Fujiwara H, Imai S, Akai S, Nizzuma K, 1992. Monoclonal antibody analysis of keratin expression in carcinomas of sweat glands. J Cutan Pathol 19: 407-414. 
Thaler M, Fukuyama K, Epstein WL, et al., 1980. Comparative studies of keratins isolated from psoriasis and atopic dermatitis. J Invest Dermatol 75: 156-158.

Thewes M, Stadler R, Korge B, Mischke D, 1991. Normal psoriatic epidermis expression of hyperproliferation associated keratins. Arch Dermatol Res 283: 465-471.

Tinsley JM, Fisher C, Searle PF, 1992. Abnormalities of epidermal differentiation associated with expression of the human papilloma virus type I early region in transgenic mice. J Gen Virol 73: 1251-1260.

VAN DE Klundert FAJM, RaAts JMH, Blomendal H, 1993. Intermediate filaments: regulation of gene expression and assembly. Eur J Biochem 214: 351-366.
Vassar R, Coulombe PA, Degenstein L, Albers K, Fuchs E, 1991. Mutant keratin expression in transgenic mice causes marked abnormalities resembling a human genetic skin disease. Cell 64: 365-380.

ViJAYALAKShMI V, GUPTA PD, 1994. Estradiol regulated transamidation of keratins by vaginal epithelial cell transglutaminase. Exp Cell Res 214: 358-366.

Yang JM, Chipev CC, DiGiovanna JJ, Bale SJ, Marekov LN, Steinert PM, Compton JG, 1994. Mutations in the H1 and 1A domains in the keratin 1 gene in epidermolytic hyperkeratosis. J Invest Dermatol 102: 17-23. 